\title{
Incidence of Third Trochanter in Human Femora and It's Morphometry in Indian Population
}

\section{Salma Sadaf ${ }^{1}$, Padmalatha $\mathrm{K}{ }^{* 2}$, Giridhar Dasegowda ${ }^{3}$, Priyanka Prasanna Kumar} Belaguthi ${ }^{4}$.

${ }^{1}$ Third year MBBS Student, ESIC Medical College \& PGIMSR, Rajajinagar, Bangalore, Karnataka, India.

${ }^{* 2}$ Associate Professor, ESIC Medical College \& PGIMSR, Rajajinagar, Bangalore, Karnataka, India.

${ }^{3}$ Third year MBBS Student, ESIC Medical College \& PGIMSR, Rajajinagar, Bangalore, Karnataka, India.

${ }^{4}$ Third year MBBS Student, ESIC Medical College \& PGIMSR, Rajajinagar, Bangalore, Karnataka, India.

\section{ABSTRACT}

Background: The third trochanter is an osseous-cartilaginous-tendinous complex. It is a term used for a prominent oval structure usually confined under the greater trochanter in the superior end of gluteal tuberosity. The third trochanter results from increased pull of the gluteus maximus. The third trochanter gives the muscle better grip, helps to alter the direction of tendon and improves effective function.

Purpose of the study: The present study was undertaken to compare the incidence of the third trochanter in human femora with other series and to correlate with its morphometry.

Materials and Methods: 56 dry human femurs (28 each of right and left side) of unknown age and sex were obtained from fellow undergraduate students at ESIC Medical College and PGIMSR, Bangalore, Karnataka, India. Trochanters with damaged upper ends were excluded from the study. After careful examination two femurs were excluded and the rest were subjected to identification of third trochanter.

Results: The incidence of the third trochanter in the present study was $14.28 \%$ with the right side predominant (10.71\%). The mean length and width were $17.87 \mathrm{~mm}$ and $7 \mathrm{~mm}$ respectively. The femurs with the third trochanter were found to have better developed greater trochanter and all the osteometric measurements were found to be higher compared to the ones without. No significant difference was noted in the morphometric indices, as all the osteometric measurements were uniformly increased.

Conclusion: This study was performed to increase the understanding of this post-cranial non metric trait on Indian population because of scarcity of information on this variation of human femora. We find the incidence more on the right side indicative of dominant side in most people. The femurs were uniformly bulkier as seen in better built human femurs. Hence, it is a change to meet the functional demands.

KEY WORDS: third trochanter, trochanter, femur, morphometry, gluteus maximus, bony projection, non-metric variant, post-cranial

Corresponding Author: Dr Padmalatha K, Associate Professor, Department of Anatomy, ESIC Medical College \& PGIMSR, Rajajinagar, Bangalore, Karnataka, India.

E-Mail: padduanat@gmail.com

Access this Article online Quick Response code

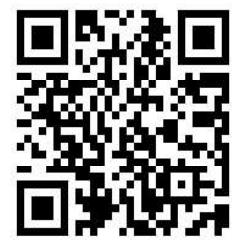

\section{Journal Information}

International Journal of Anatomy and Research

ISSN (E) 2321-4287 | ISSN (P) 2321-8967

https://www.ijmhr.org/ijar.htm

DOI-Prefix: https://dx.doi.org/10.16965/ijar

Article Information

Received: 05 Jan 2021

Peer Review: 06 Jan 2021

Revised: None
Accepted: 22 Feb 2021

Published (O): 05 Mar 2021

Published (P): 05 Mar 2021 


\section{INTRODUCTION}

The third trochanter is described as an oblong, conical or rounded elevation of bone which can be a continuity of gluteal ridge [1]. It can be identified in most cases lateral to the imaginary line connecting tip of greater trochanter and superior bifurcation of linea aspera [2]. The third trochanter is the site of attachment of ascending tendon of gluteus maximus. It serves to increase the surface area of attachment increasing the efficacy of muscle contraction. The expression of third trochanter results from increased pull of the gluteus maximus as seen in better built human femurs. When present, the third trochanter helps in strong mechanical effort of the joint in extension, lateral rotation and medio-lateral reinforcement to withstand stress during locomotion and erect posture [3]. It also plays an important role as a useful landmark for biomechanical and densitometry studies and as the access point of choice to approach the medullary cavity $[4,5]$. It is used as a non-metric variation in the post-cranial skeleton which can be used in discrimination of different human population [6].

A study shows correlation between muscle insertion and break lines topography in pertrochanteric fractures. The study states that the resistance to fracture is much less when bone is covered with only periosteum without any reinforcing elements like muscles and ligaments [7].

The present study aims in finding the incidence of this variation of femora in Indian population along with correlation with its morphology and morphometric indices.

\section{MATERIALS AND METHODOLOGY}

56 dry human femurs (28 each of right and left side) of unknown age and sex were obtained from fellow undergraduate students at ESIC Medical College and PGIMSR, Bangalore, Karnataka, India. Trochanters with damaged upper ends were excluded from the study. After careful examination two femurs were excluded and the rest were subjected to identification of third trochanter. Only presence of a prominent oval projection with well-defined margins separate from gluteal ridge were included (Figure 1). Readings taken included 9 measurements from Standard Anthropometry Handbook (Figure 2) repeated 3 times for each bone to reduce error using a Digital Vernier Calliper (least count of $0.01 \mathrm{~mm}$ ), infant statiometer and measuring tape. The photographs were taken using Nikon DSLR camera and MATLAB ${ }^{\circledR} 2018$ B software was used for data analysis.

\section{The following osteometric measurements were taken (Figure 2):}

1. Natural femur length (M2)

2. Femoral shaft length (M5)

3. Transverse femoral shaft diameter (M7)

4. Middle shaft circumference (M8)

5. Femoral neck circumference (M17)

6. Femoral Head Height (M18)

7. Femoral head width (M19)

8. Sagittal length of Greater trochanter (SG)

9. Coronal length of Lesser Trochanter (CL)

Using the above measurements, 5 morphometric indices were calculated:

1. Femoral Massiveness index $(F M I)=M 8 / M 2 x$ $100 \%$

2. Shaft Massiveness Index $(\mathrm{SMI})=\mathrm{M} 8 / \mathrm{M} 5 \mathrm{x}$ $100 \%$

3. Neck Massiveness Index(NMI) $=$ M17/M5 $\mathrm{x} 100 \%$

4. Femoral Head Index(FHI) $=(\mathrm{M} 19 / \mathrm{M} 2) \times 100 \%$ Head Massiveness Index(HMI) $=(\mathrm{M} 18+\mathrm{M} 19) /$ $\mathrm{M} 2 \times 100 \%$

\section{RESULTS}

Of 56 femora studied, it was observed that the third trochanter was found in eight bones (14.28\%), two belonging to the left side (3.57\%) and six to the right (10.71\%) (Figure 3). The mean length and width of third trochanter was $17.87 \mathrm{~mm}$ and $7 \mathrm{~mm}$ respectively. The mean values of basic measurements in femora with the third trochanter were much higher compared to the femora without the third trochanter (Table 1). Sagittal length of the greater trochanter (SG) and coronal length of the lesser trochanter ( $C L)$ measurements performed on femora with the third trochanter were found to have greater dimensions than femora without the third trochanter(Table 1). 
Table 1: Results of osteometric measurements.

\begin{tabular}{|c|c|c|c|c|c|c|c|c|c|}
\hline $\begin{array}{c}\text { Osteometric } \\
\text { Measurement }(\mathrm{mm}) \\
\mathrm{p}<0.05\end{array}$ & M2 & M5 & M7 & M8 & M17 & M18 & M19 & SG & $\mathrm{CL}$ \\
\hline \multicolumn{10}{|l|}{$\begin{array}{c}\text { With Third } \\
\text { Trochanter } n=8\end{array}$} \\
\hline Mean & 480.5 & 321.3 & 26.3 & 83.9 & 103.2 & 41.2 & 41.6 & 38.7 & 21.41 \\
\hline Standard deviation & 20.3 & 15.1 & 2.3 & 5.8 & 7.8 & 2.2 & 2.6 & 4.5 & 2.6 \\
\hline $1^{\text {st }}$ Quartile & 478.3 & 315.3 & 24.4 & 79.3 & 96.1 & 39.5 & 40.3 & 36.2 & 19.8 \\
\hline Median & 484 & 320.5 & 26.2 & 82.8 & 102.9 & 41.1 & 41.3 & 38.8 & 20.7 \\
\hline $3^{\text {rd }}$ Quartile & 492.2 & 332.5 & 28.1 & 89.3 & 110.1 & 43.2 & 43.7 & 42.4 & 22.1 \\
\hline \multicolumn{10}{|l|}{$\begin{array}{l}\text { Without Third } \\
\text { Trochanter } n=48\end{array}$} \\
\hline Mean & 454.3 & 303.6 & 24.9 & 78.9 & 96.6 & 40.1 & 39.7 & 36.1 & 20.1 \\
\hline Standard deviation & 20.4 & 16.2 & 2 & 4.5 & 11.3 & 2.8 & 2.9 & 2.9 & 2.1 \\
\hline $1^{\text {st }}$ Quartile & 437 & 292.5 & 23.4 & 76.5 & 86.6 & 38.3 & 37.3 & 33.7 & 18.6 \\
\hline Median & 454.3 & 303.7 & 24.8 & 77.7 & 95 & 40.2 & 39.7 & 35.5 & 20.1 \\
\hline $3^{\text {rd }}$ Quartile & 469.3 & 315.7 & 26.2 & 82.2 & 105.4 & 41.7 & 41.4 & 37.7 & 21.6 \\
\hline
\end{tabular}

Table 2: Calculated morphometric indices.

\begin{tabular}{cccccc}
\hline $\begin{array}{c}\text { Morphometric } \\
\text { Index }\end{array}$ & FMI & SMI & NMI & FHI & HMI \\
\hline \multicolumn{5}{c}{ With } & Third Trochanter $\mathbf{n = 8}$ \\
\hline Mean & 18.6 & 26.1 & 32.2 & 9.2 & 18.4 \\
\hline Standard deviation & 0.8 & 1.6 & 3.3 & 0.3 & 0.6 \\
$\mathbf{1}^{\text {st }}$ Quartile & 18.1 & 24.9 & 30.1 & 9 & 18.1 \\
\hline Median & 18.7 & 25.7 & 30.5 & 9.1 & 18.4 \\
$\mathbf{3}^{\text {rd }}$ Quartile & 19.3 & 27.6 & 34 & 9.5 & 18.8 \\
& Without & Third Trochanter $\mathbf{n}=48$ & & \\
Mean & 18.6 & 26 & 31.9 & 9.4 & 18.8 \\
\hline Standard deviation & 1.1 & 1.4 & 3.8 & 0.7 & 1.2 \\
$\mathbf{1}^{\text {st }}$ Quartile & 17.8 & 25.2 & 29.1 & 9 & 18.1 \\
Median & 18.7 & 25.9 & 31 & 9.2 & 18.5 \\
$\mathbf{3}^{\text {rd }}$ Quartile & 18.9 & 26.5 & 34.3 & 9.7 & 19.4 \\
\hline Significance & $\mathrm{P}<0.05$ & - & - & $\mathrm{P}<0.05$ & $\mathrm{P}<0.05$ \\
\hline
\end{tabular}

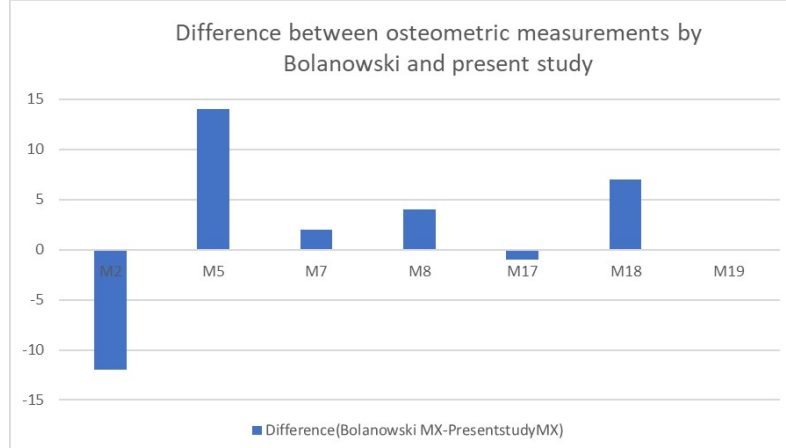

Graph 1: Difference between Osteometric measurements by Bolanowski and present study.
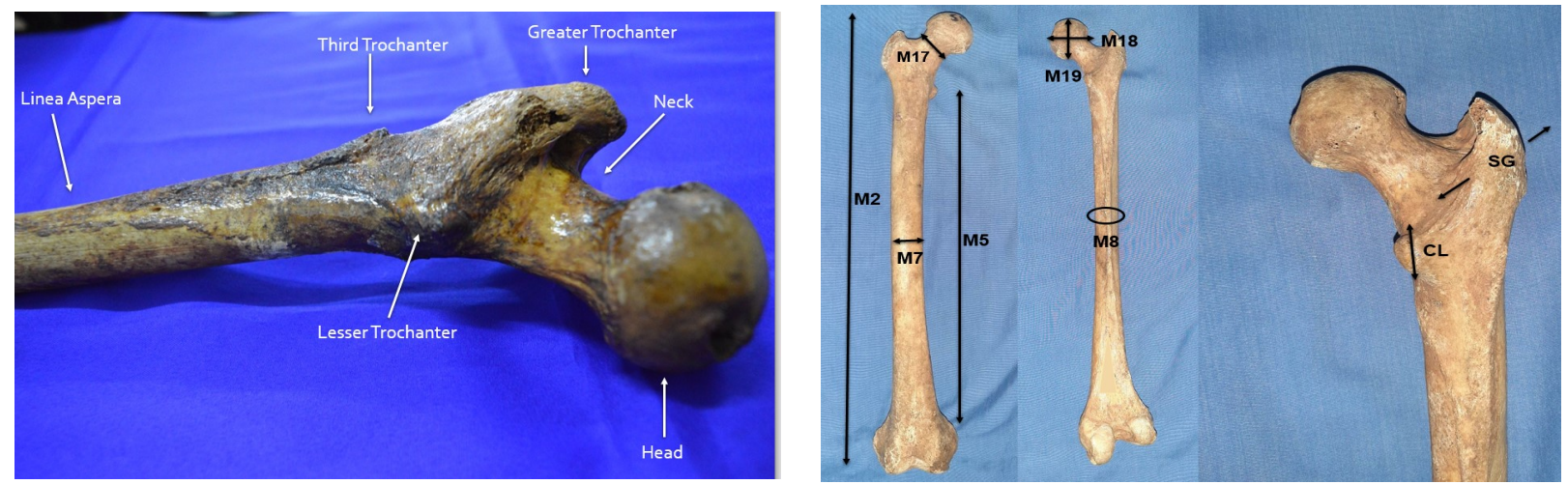

Fig. 1: Human Femur with prominent third trochanter.

Fig. 2: Osteometric measurements of human femora.

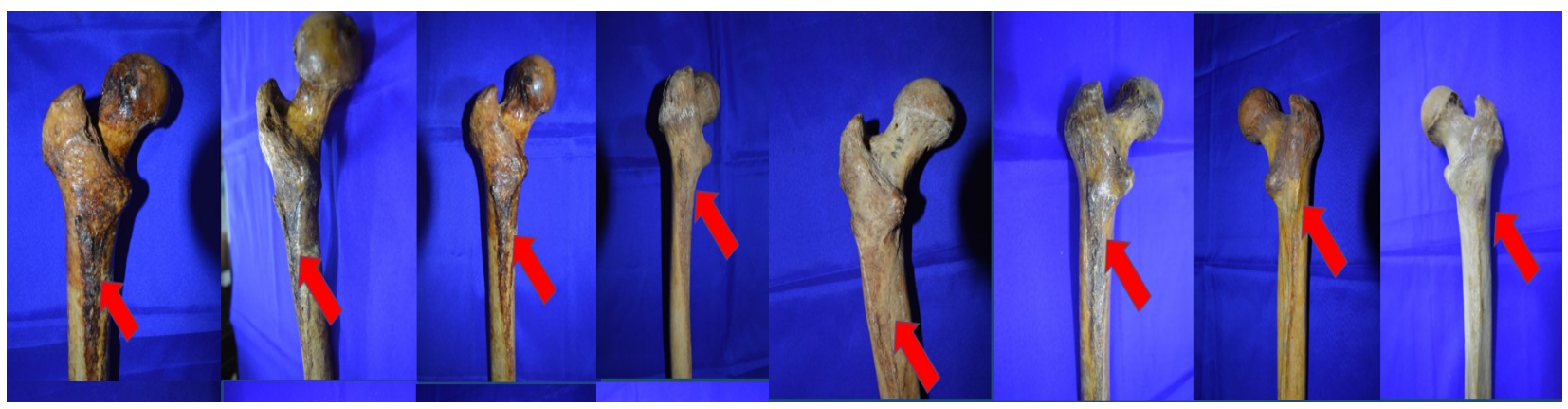

Fig. 3: The human femurs containing the third trochanter in the present study 
Harsimarjit Kaur, Rimple Bansal, Gurdeep S Kalyan, Ruchi Goyal. Morphology of Piriformis- its clinical implications in Piriformis syndrome.
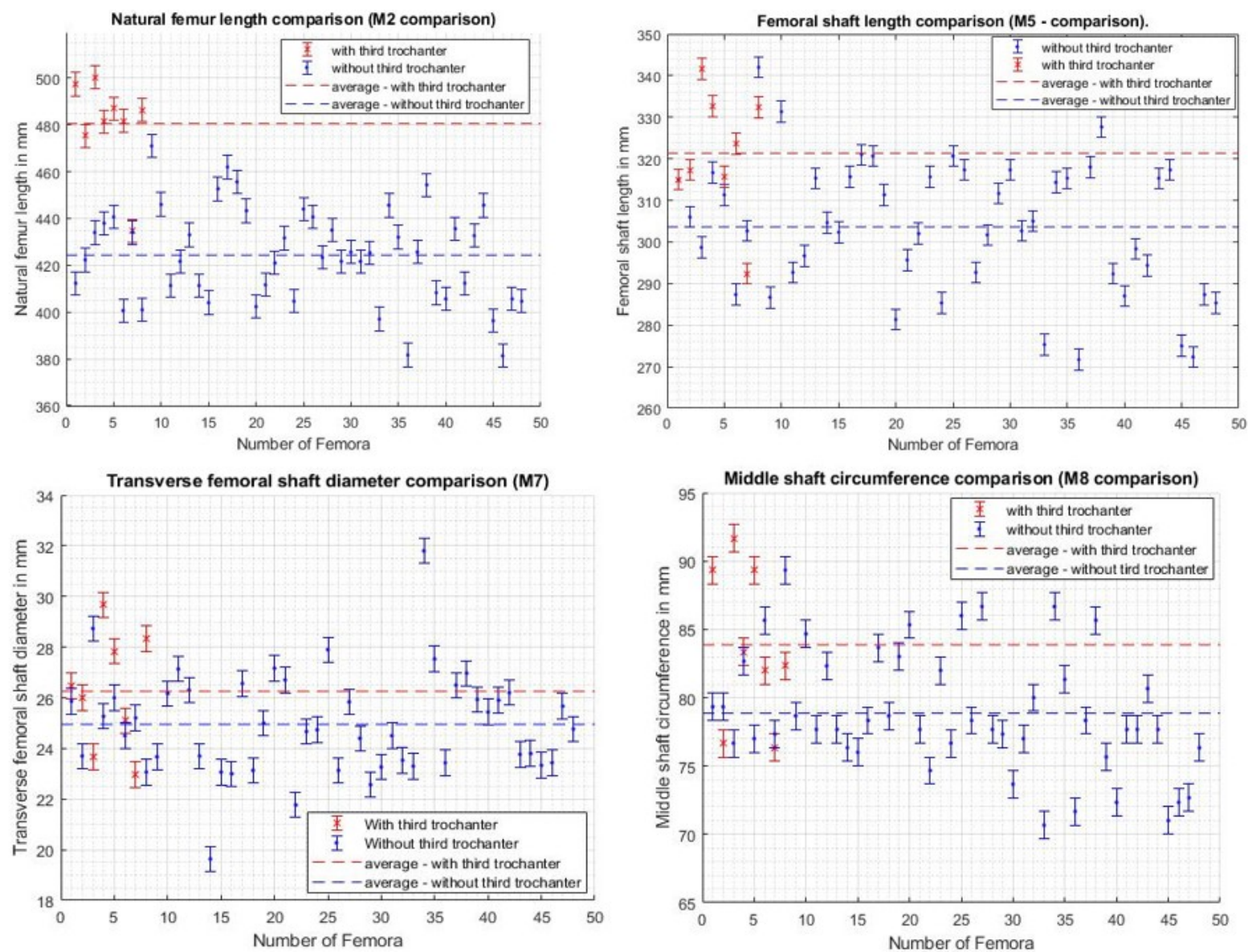

Fig. 4: Graphs comparing osteometric measurements (M2, M5,M7,M8) between femurs with the third trochanter and without
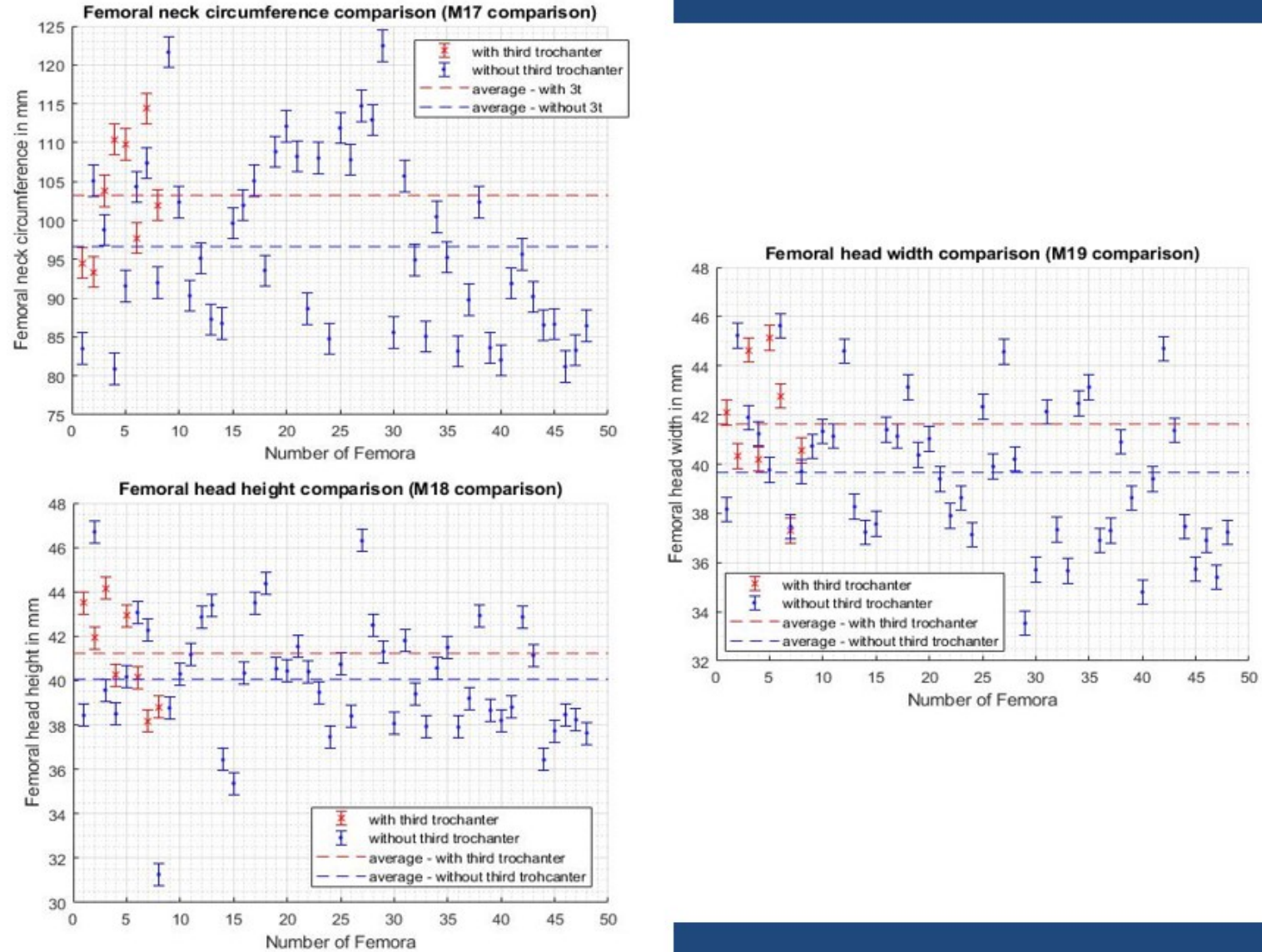

Fig. 5: Graphs comparing osteometric measurements(M17, M18,M19) between femurs with the third trochanter and without 
The morphometric indices of both groups were found to be similar because of overall equal increase in all osteometric measurements (Table 2). The osteometric measurements were compared between femurs with the third trochanter and femurs without the third trochanter using graphs (Figure 4 and 5).

\section{DISCUSSION}

The findings recorded from the present study were compared with previous studies and the following results were noted:

The incidence of the third trochanter in the present study is found to be $14.28 \%$ similar to other studies conducted on Northern Tamil Nadu population (13.72\%) [8], on Pakistani population (13.9\%) [9] and study by Rajad $R$ (13\%) [10]. The incidence was much higher than the study by Ghosh et al in general Indian population (6.6\%) [11], by Bolanowski on polish population (6.1\%) [3] and on North Karnataka population (4.43\%) [12]. Incidence varies from $17 \%$ to $72 \%$ depending on ethnicity [3].

The average length and width of the third trochanter in the present study was $17.87 \mathrm{~mm}$ and $7 \mathrm{~mm}$ respectively. Similar finding were seen by Muthukumaravel $\mathrm{N}$ in northern Tamil Nadu region with a mean length of $19.80 \mathrm{~mm}$ and width of $7.63 \mathrm{~mm}$. The study also showed mean length was higher on the right side and mean width was greater on the left [8].

No significant difference is seen in the calculated morphometric indices suggesting no correlation of the third trochanter with morphological features of femoral head, neck or shaft. There is an increase in dimensions of all osteometric measurements from $\mathrm{M} 2$ to M19 leading to no significant alteration in calculated morphometric indices. Femurs with the third trochanter were found to have a better developed greater trochanter. This implies that femurs with the third trochanter are larger and bulkier compared to the ones without. A similar result was also found in the study on Polish population [3]. The graph 1 showing the mean morphological value difference between the study conducted by Bolanowski and the present study. Apart from $\mathrm{M} 2$ and $\mathrm{M} 19$ all other morphological measurements are greater in the present study.

The third trochanter is present in other mammal species like whales, rats, and rabbits as well. It was also found in the Neanderthals but not in the other species of anthropoids [3]. No conclusions have yet been made about the progressive or regressive nature and the evolutionary significance. Bolanowski also in his study suggested that the third trochanter is because of altered gluteus maximus function rather than micro-evolution of skeleton or progressive morphological feature [3].

Many studies have shown various environmental and biological factors influencing on these postcranial non-metric traits like age, sex, side dependence and nutrition [13-15]. A study showed a side variation in whites and blacks. Right side was found to be more common in whites and left side in blacks [4]. Right side was found to be more common in the present study. It could be because of preferential use of the right side as the third trochanter is believed to be a change to meet the functional demands. Previous studies have shown the prevalence to be higher in females but sex is found to have no significant association [6].

The third trochanter reinforces muscle attachment making bones resistant to fracture onset compared to bones covered by only periosteum [7].

A study conducted on armadillo femurs subjected to forces in coronal plane showed that muscles attached to the third trochanter were able to counter the bending strains in loaded femur [16].

The mechanical stress exerted by the gluteus maximus is said to contribute in the expression of the third trochanter. In response to increased ground reaction force, the third trochanter functions to provide increased skeletal mass as a reinforcement mechanism for the proximal end of femur [1]. The gluteus muscle decreases limb speed during locomotion especially in late swing and heal strike phase [17].

The expression of the third trochanter is mainly influenced by physical activity and can provide information about environmental 
stimuli exerted by that particular population [1]. Hence, it is a useful nonmetric trait which can be used to compare human populations.

\section{CONCLUSION}

The present study provides a morphometric data and morphological differences in femurs with third trochanter and its clinical importance. Therefore, we conclude that the incidence is higher on the right side maybe correlating with preferential use of right side of body. The greater trochanter is better developed in femurs with third trochanter. The third trochanter may serve to increase surface area of attachment for the gluteal musculature, indicating medio-lateral reinforcement and resist high mechanical stress in erect posture and locomotion. Identification of third trochanter on imaging be a useful landmark for biomechanical and densitometry studies, as the access point of choice to approach the medullary cavity and can be used for intramedullary nailing and reaming, for bone marrow aspirations and catheterization.

\section{ACKNOWLEDGEMENTS}

The authors are thankful to Naeem Ahmed, Carleton University (Bachelors in Physics Major and Mathematics Minor) for the contribution to the paper with advanced level of statistical analysis and graphical representation using MATLAB ${ }^{\circledR} 2018 \mathrm{~B}$. The authors are also thankful to students of ESIC medical college \& PGIMSR, Bangalore and Dr. Biswabina Ray, Professor \& HOD, Department of Anatomy for encouraging and supporting us to carry out this study.

\section{Conflicts of Interests: None}

\section{REFERENCES}

[1] Lozanoff S, Sciulli PW, Schneider KN. Third trochanter incidence and metric trait covariation in the human femur. J Anat. 1985;143:149-59.

[2]. Chhaparwal R, Bhadkaria V, Chhaparwal N. Incidence of third trochanter/crista glutei in human femora in Central Indian population. Journal of Krishna Institute of Medical Sciences University. 2017; 6. 57-62.

[3]. Bolanowski W, Smiszkiewicz-Skwarska A, Polguj M, Jedrzejewski KS. The occurrence of the third trochanter and its correlation to certain anthropometric parameters of the human femur. Folia Morphol (Warsz). 2005;64(3):168-75.
[4]. Kurth AH, Wang C, Hayes WC, Shea M. The evaluation of a rat model for the analysis of densitometric and biomechanical properties of tumor-induced osteolysis. J Orthop Res. 2001;19(2):200-5.

[5]. Meyer RA Jr, Tsahakis PJ, Martin DF, Banks DM, Harrow ME, Kiebzak GM. Age and ovariectomy impair both the normalization of mechanical properties and the accretion of mineral by the fracture callus in rats. J Orthop Res. 2001;19(3):428-35.

[6]. Finnegan M. Non-metric variation of the infracranial skeleton. J Anat. 1978;125(Pt 1):23-37.

[7]. Bartoska R, Baca V, Kachlik D, Marvan J, Dzupa V. The correlation between muscles insertions and topography of break lines in pertrochanteric fractures: a comprehensive anatomical approach of complex proximal femur injuries. Surg Radiol Anat. 2013;35(10):957-62.

[8]. Muthukumaravel N, Manjunath KY. A study on occurrence of third trochanter in the femora in northern Tamil Nadu region. National Journal of Clinical Anatomy. 2015;04(04):186-9

[9]. Aziz N, Nadeem T, Mubarik A. A Study of Third Trochanter in Femora of Pakistani Population. Annals KEMU. 2020Jul;2(1\&2):8-11. Available from: https://annalskemu.org/journal/index.php/annals/article/view/3544

[10]. Rajad R, M RR, Romi S. A study on the occurrence of human femoral third trochanter. Indian J Clin Anat Physiol. 2017;4(3):316-8.

[11]. Ghosh S, Sethi M, Vasudeva N. Incidence of third trochanter and hypotrochanteric fossa in human femora in Indian population. OA Case Reports 2014 Feb 25;3(2):14.

[12]. Sylvia S, Ahmed MK, Jainapur P. Third trocanter of human femora in north karnataka region. Int J Anat Res. 2015;3(2):1011-4.

[13]. Dahinten SL, Pucciarelli HM. Effect of age, sex and nutrition on discontinuous traits of rat skull. Acta Anat (Basel). 1981;110(2):159-63.

[14]. Ossenberg NS. The influence of artificial cranial deformation on discontinuous morphological traits. Am J Phys Anthropol. 1970;33(3):357-71.

[15]. Corruccini RS. An examination of the meaning of cranial discrete traits for human skeletal biological studies. Am J Phys Anthropol. 1974;40(3):425-45.

[16].O'Higgins P, Milne N. Applying geometric morphometrics to compare changes in size and shape arising from finite elements analyses. Hystrix. 2013;24(1):126-32.

[17]. Lovejoy CO, Heiple KG, Burstein AH. The gait of Australopithecus. Am J Phys Anthropol. 1973;38(3):757-79.

How to cite this article: Salma Sadaf, Padmalatha K, Giridhar Dasegowda, Priyanka Prasanna Kumar Belaguthi. Incidence of Third Trochanter in Human Femora and It's Morphometry in Indian Population. Int J Anat Res 2021;9(1.3):7890-7895. DOI: 10.16965/ ijar.2021.101 